\title{
X. Fragmentarische Erinnerungen eines alten Archivars.
}

\author{
Von \\ Dr. Louis Spach, \\ Bezirksarchirdirektor in Strassburg.
}

In der zweiten Hälfte des Dezembermonats 1839 traf mich in Paris, durch Vermittlung des Maires von Strassburg ein Vorschlag des Präfecten des Niederrheins, als Departementalarchivar einzutreten, nebenher auch die Geschăfte des Kabinets des hohen Beamten zu besorgen. Ich war damals in der französischen Hauptstadt gerade nicht unbeschäftigt, doch auf literarische Arbeiten beschränkt; eine naheliegende Aussicht auf eine Bibliothekarsstelle in Paris schien zwar erwünscht ... ich zog die Heimath vor, nach kurzer Ueberlegung. Der fieberhaft aufregenden Existenz war ich vorderhand wenigstens überdrüssig; in der Heimath, so dachte ich, erwarten mich sonnige, ruhige Tage; zum voraus fühlte ich mich angeweht und abgekühlt von dem Balsamduft der Tannenwälder der Vogesen und des Schwarzwaldes; wissenschaftliche Verbindungen mit Paris blieben ja zu Recht bestehen. Ich schnürte meinen kleinen Reisebündel, bestieg den Courier de la malle, und am Stephanstage war ich in der lieben Vaterstadt.

Es sollte Vieles ganz anders kommen, als ich mir vorgespiegelt. Die Tage des Schlaraffenlebens verloren sich bald in weiter Ferne. Es wäre auch etwas verfrüht gewesen, mit neununddreissig Jahren schliesst man sich noch nicht rom thätigen Leben ab.

Einige Ruhetage gönnte ich mir; am Dreikönigsabend 1840 besprach ich mich zum ersten Mal mit meinem künftigen Chef und 
Gönner. Ich fand mich einem bereits hoch in den Vierzig stehenden gut conservirten Manne gegenüber, dessen Vater mit den Girondins in Bordeaux verbrüdert, in seiner Heimat eine Rolle gespielt, und dessen Geist auf seine Söhne übergegangen war. Herr Louis Sers, der dritte Sohn, hatte als Präfect der Loire 1834 einen Arbeiteraufstand bewältigt. Autorităt und Gewohnheit des Befehlens stand auf seiner Stirne geschrieben; um seine Lippen spielte, wenn es ihm genehm, ein wohlwollendes Lächeln.

sIch habe Sie als Archivar hieher berufen,* so begann er; sder Departementalrath hat die Fonds dazu voriges Jahr bewilligt. Es ist eine Misère; ich muss Ihren mässigen Gehalt aus meinem Abonnement ${ }^{1}$ ) ergänzen. Den Augiasstall des Archirs bringen Sie in ihren Nachmittagsstunden so viel als möglich in Ordnung; viel unnützen Plunder schaffen Sie weg in öffentlicher Versteigerung; lassen Sie die Schreibereien nicht anwachsen. In meinem Kabinet concentrire ich die wichtigsten, die anziehendsten Geschäfte; finde ich Sie, wie mir der Maire von Strassburg die Zusicherung giebt, dazu tūchtig, so werden Sie mir zur Hand gehen. Der Maire Schützenberger ist Ihr Jugendfreund; wir sind bisweilen in Conflikt; da können Sie vermitteln. Dann haben die Conservateurs hier eine Zeitung gegründet, dazu liefern Sie archivalische Beiträge, interessante, geschichtliche Dokumente. Die Elsasser sind eingefleischte Lokalpatrioten; sie lieben, mit vollem Recht, ihre schöne Provinz; das wird Ihnen, Herr Archivar, zu Gute kommen, Ihnen Freunde zuwenden, uns Freude machen. Dann habe ich einen zwanzigjährigen Sohn; er verliess unlängst die polytechnische Schule; ich bestimme ihn zum Verwaltungsfach, er sieht sich um, arbeitet alternative in den verschiedenen Bureaux; auch bęi Thnen wird er sich einstellen. Seien Sie ihm ein guter Freund und brüderlicher Lehrer; er ist bisweilen leidenschaftlich, aber ein grundehrlicher Junge. Sie haben sich, wie ich vernehme, auch im Privaterziehungsfache versucht."

So sah ich mich, ab ovo, nicht nur als Archivar eingeführt; ich mochte wollen oder nicht, laufende Geschäfte, Zeitungsbeiträge wurden mir zu Theil, keineswegs $\mathrm{zu}$ meinem Leidwesen. Je mehr ein Archivbeamter Einsicht erhält in die Tagesinteressen, desto mehr wird er zur Würdigung der modernen Akten befāhigt. Auch

1) So wurde die Summe benannt, welche die Regierung zur Besoldung der Präfekturbeamten anwies; $1 / \varepsilon$ derselben war der Präfekt anzuwenden verpflichtet. 
auf die Vergangenheit wirft das Verständniss der Gegenwart leuchtende Reflexe.

Vorerst galt es jedoch, eine Rundschau zu halten in meinem künftigen officiellen Gebiet. Das Archiv selber, seinen allgemeinen Inhalt musste ich übersehen, wissen, wer vor mir dort gewaltet, was gethan, was zu thun erübrigte.

In den ersten Jahren nach der Revolution von 1789 hatten geistliche und weltliche Behörden des Elsass auf Befehl der Regierung ihre Dokumente in Strassburg hinterlegt. So war das ehemalige Archiv des Bisthums, so waren die Kollektaneen aller Abteien, Klöster, geistlicher Orden des Niederrheins, so die Akten der herrschaftlichen deutschen Regierungen, die nach dem westphälischen Frieden im Elsass zu Recht bestanden, in Strassburg aufgestapelt 1). Man wies diese Masse von Documenten vorläufig in eine Lokalităt, welcher eine geschichtliche Bedeutsamkeit zukam. Nordwestlich von dem palastähnlichen Gebäude der früheren königlichen Intendance d'Alsace lag der mittelaltrige Kornspeicher der Stadt, ein von kleinen, kümmerlichen Ogival-Fensterlucken durchbrochener, kasernenartiger Bau. Seit der Mitte des 15. Jahrhunderts erhob sich dieses Magazin auf derselben Stelle, wo hundert Jahre zuvor (1349) während der schändlichen Judenhetze der revolutionäre Mord von zweitausend Israeliten vollzogen wurde. Eines geschichtlichen Untergrundes, eines verkohlten Scheiterhaufens ermangelte somit die bedeutsame Localität nicht. Mit der innern Einrichtung war es nicht geradezu schlecht bestellt; doch für comfortable Arbeit in Wintersund Sommerszeit wenig gesorgt. Ueberdies störte das nördlich gegenüberliegende Schauspielhaus durch seine musikalischen Uebungen die zu stiller, ernster Sammlung angehaltenen Beamten. Der Corıtrast war schreiend; drüben die Weil mil ihrer Lust, diesseits der Esplanade die gefängnissähnlichen Räume mit geisttödtender Arbeit.

Die zwei Stockwerke fand ich für die bereits angeschwollene Materie sehr enge; nach kurzer Zeit sollte ich inne werden, mit welch' sparsamer Genauigkeit ein bedrängter Archivist verfahren muss, wenn er nicht unter der Wucht der Papiere und der Obliegenheiten ersticken will.

1) Theilungen mit dem Oberrhein fanden, zu wiederholten Malen, etwas spāter statt. 
Im bischöflichen Archiv hatte vor der Revolution ein jetzt allgemein bekannter Gelehrter, ein junger Priester gewaltet, Abbé Grandidier, eine liebenswürdige Erscheinung, fast ein Wunderkind zu nennen. Stand er doch bereits, kaum neunzehn Jahre alt, im Amte, verzeichnete unermüdlich die geschichtlichen Schătze der kirchlichen Vergangenheit des Elsass und hinterliess, als er im 35. Jahre von dem Schauplatz seiner irdischen Wirksamkeit schied, in $\mathbf{3 6}$ kalligraphirten Foliobānden das analystische Repertorium der damals vorliegenden Dokumente. Durch eine seltne providentielle Vergünstigung blieb, inmitten der über Strassburg ergangenen Katastrophen, diese unschätzbare Sammlung in ihren Hauptbestandtheilen erhalten.

Weit ausgedehnter war indess Grandidier's Wirkungskreis; er bildete sich zum Geschichtsschreiber und Antiquar. Die ersten Jahrhunderte der elsassischen literarischen, geistlichen und weltlichen Annalen, auf Originalien fussend, an der Quelle schöpfend, erzählte er in elegantem, französischem Style. Leider unterbrach sein früher Tod die weitschichtig angelegte Arbeit. Seine Beschreibung der Strassburger Kathedrale, in einem Bande, lässt auf dem jetzigen Standpunkt der Wissenschaft manches zu wünschen übrig, ist indess nach Schade's Mūnsterbūchlein als bahnbrechend zu betrachten. Zum historischen Kritiker war er vielleicht berufen, aber durch seinen Stand eingeengt, im Herzensgrunde freisinnig, gegen Neid und Verlästerung ankāmpfend. Von einem der Kardinalbischöfe von Strassburg beschützt, verfiel er bei dessen Nachfolger, dem berüchtigten Rohan, in Ungnade. Sein plötzliches Hinscheiden, während einer gelehrten Inspectionsreise in einem Kloster an der Grenze der Freigrafschaft Burgund, konnte man seiner übermässigen Arbeitsamkeit, zum Theil den nagenden Kummer zuschreiben; der Verdacht von Vergiftung blieb nicht aus.

Mir wurde Grandidier's Gestalt von allem Anfang an sympathisch. Obgleich er nie in denselben Räumen gewandelt und gearbeitet hatte, schien mir seine Gegenwart zweifellos. Er ward mir zum erwünschten Vorbilde.

Bedauernswerth fand ich einen andern Vorgänger, Abbé Brendel, der, zum conslitutionellen Bischof im ersten Rerolutionsjahre befördert, neben dem Maire Fritz von Dietrich, von ihm unterstützt, einige Zeit sich gegen den Hass der rechtglāubigen Klerisei aufrecht hielt, darauf von dem Terroristen Eulogius Schneider bei Seite geschoben, seine ephemere Würde in einem obscuren Beamtenleben abbüsste. 
Er wurde nach hergesteliter Ordnung zum Distriktsarchivar ernannt, und bezog einen höchst geringen Gehalt.

Während des ersten Kaiserreichs versahen Beamte des Präfecten das völlig unbeachtete Bureau des Archivs. So schlecht waren sie besoldet, dass unter der Restauration sich einige zum Missbrauch ihrer Stellung verleilen liessen. Das Wachs vieler Pergamentsiegel hatten sie abgeschnitten und als gemeine Waare verhandelt. Einer der Beschuldigten war durchaus nicht unbegabt: er schrieb französische Prosa und dichtete in deutschen Versen, siechte hin, brustkrank, da er sich in seiner Ehre und Existenz bedroht sah, und starb im Būrgerhospital.

Eine vorläufige, nach Materien geordnete und in Kartons vertheilte Einreihung der Kloster-Archivalien wurde etwas später durch einen tüchtigen Arbeiter, Lauth, unternommen; vollstāndig war nichts, und von einer chronologischen Inventarisirung keine Rede. Mir kam jedoch diese Vorarbeit zu gute. Gegen Ende des ersten Jahres meiner Einbürgerung konnte ich mit der Analyse dieser unbekannten Schätze beginnen und durch jährliche Berichte an Präfecten und Generalrath den jedesmaligen Stand der fortschreitenden Arbeit bezeichnen.

So stellt sich bei der Art Benedictinerarbeit immer der Eine gezwungen auf die Schultern des Andern; glücklich sind die Abgeschiedenen oder zu den Invaliden Geschobenen, wenn der Nachfolger ihrem Streben gerecht wird.

Bei meinem Eintritt in's Amt fand ich zwei Angestellte vor, die ausschliesslich mit dem Laufenden, dem Nachsuchen und womöglich Auffinden sich beschäftigten. Der Eine war nicht klassisch gebildet, aber ein zuverlässiger, diskreter Charakter. Ich hatte das Glück, nach etwa dritthalb Jahren ihm zu einer Anstellung in der Kanzlei der franzósischen Gesandtschaft zu Bern zu verhelfen. Es war ein für ihn passenderes Amt, das er jahrelang zu Bern, später in Dresden versah.

Der andere Archivbeamte hatte von der Pike auf gedient, hatte nicht die geringste Erziehung oder Bildung von Haus aus erhalten, aber sich so gut in die tăglichen Vorkommnisse hineingearbeitet, dass er, besonders den ländlichen Kunden und Nachfragen gegenüber, sich als trefflicher Vermittler bewährte. Der letzte französische Präfect verabschiedete ihn trotz meiner Einrede; versagt wurde mir sogar die Genugthuung, dem ergrauten Diener eine Denkmūnze für fünfzigjährige Leistung vor dem Personal der Präfectur zu überreicheń. 
Es sind mir nach und nach mehrere verdienstvolle, auch mittelmässige Mitarbeiter zur Seite gestanden. Ich unterliess es nie, das Geleistete öffentlich anzuerkennen; häufig that ich darin des Guten zu viel, bereue aber mein Verfahren keineswegs, obgleich einige Betheiligte ihre Leistungen über den reellen Werth anzuschlagen nicht ermangelten. Im menschlichen Herzen liegt nun einmal die Selbstüberschätzung.

Meiner doppelten und dreifachen Verpflichtung gegen meinen günstig gesinnten Obern suchte ich, so viel in meinen Kräften lag, nachzukommen. Begonnen wurde mit der Veröffentlichung einiger lateinischer und deutscher Urkunden, wobei ich an Stätten anknūpfte, die mir schon früher lieb waren. Die Versuche fielen nicht ungünstig aus. So wurde ein Rundschreiben des Bischofs von Strassburg, zum Bau der Münsterfaçade auffordernd (a. 1275), herausgegeben, so eine das Hospiz von Esch a u betreffende Urkunde (778), eine Liga elsassischer Dynasten gegen die Armagnaken (1436), eine päpstliche Bulle Alexanders III. zu Gunsten der Probstei Ittenwiler (1179). Hatte ich doch in den Klostergärten, die man jetzt zum pittoresken Landsitz umgewandelt, mehrere genussreiche Herbstferien verlebt! Seitdem lagerte sich der von 1870 aufgewirbelte Staub über die schöne Erinnerung und trübte sogar den Rückblick auf längst vergangene Geschichte.

In des Präfecten näherer Umgebung befreundete ich mich mit den Hauptinteressen des unterelsassischen Landstrichs. Die Rheinkorrektion und Eindāmmung des launenhaften Flusses, die Innung der Rheinschiffer, die Kanalbauten, das Unterrichtswesen, die Gefăngnisse, die Einleitung zum Bau der Pariser Eisenbahn wurden mir, so weit sie die Departementalverwaltung angingen, nach und nach anvertraut. Auf diesem mobilen Tagesgebiet fand ich, obne das Archiv zu vernachlässigen, eine oft erwünschte Zerstrenung, ein Gegengewicht gegen die spezifische Schwere veralteter Scripturen und Convolute.

Bereits im Frühjahr 1841 erliess Herr Sers eine Verfügung, es sollten die ländlichen Archive besichtigt werden, und übertrug mir, noch ein Jahr vor dem ministeriellen Erlass derselben Richtung, die Inspicirung dieser ganz verwahrlosten Gemeinderegistraturen. Ein giftiger junger Pamphletscribent schimpfte auf diese Initiative, die nur darauf berechnet sei, sdem Archivar einige Ferienreisen $\mathrm{zu}$ bezahlen . Ich liess mich durch den knabenhaften Angriff nicht an- 
fechten und besuchte zunächst die in der Lmgebung der Stadt und im Bereich der nunmehr eröffneten Basler Eisenbahn gelegenen Dorfschaften. In den verschiedenartigsten Lokalen waren die Documente und Register aufbewahrt oder verzettelt; selten in den Gemeindehāusern, meist in Kammern oder Kisten der Pfarreien, der Schulgebäude oder bei den jeweiligen Maires. Da sich die Besuche öfters auf dem oder jenem Punkte wiederholten und auf Ordnung gedrungen wurde, so befiel den betheiligten Beamten etwas Furcht vor der Verantwortlichkeit. Gerade das war gewünscht. Einmal wurde mir beim Beginn dieser Umzüge meine Befugniss bestritten. Ich hatte die wohlhabenden Dörfer am Fusse der Hausbergerhügel besucht und war nach Mundolsheim gelangt. Hier war der protestantische Schullehrer zugleich Sekretār der Gemeinde, eine gedrungene, markige Gestalt. Er fragte ziemlich unwirsch: sSie sind doch mit einem legalen Auftrag versehen? Ich trug dem berechtigten, aber etwas groben Frager die Ausfertigung des Dekrets vor; er fügte sich willig und zeigte mir eine in gutem Stande gehaltene Registratur. Ich war nicht karg in der Belobung, und die Figur des alten vierzigjährigen, braven Schulmannes blieb mir im Gedächtniss; ihn selbst sollte ich nicht mehr sehen. Im Jahre 1863 besuchte ich die hochgelegene Kirche von Mundolsheim und fand auf dem anstossenden Friedhof ein Kreuz auf frischem Grabe, vom Jahre vorher. Der Arme hatte das Zeitliche gesegnet und liess mir gewissermassen einen Stachel in der Brust und eine ernste Mahnung obendrein. Stand doch der Abgeschiedene mit mir ungefähr in gleichem Alter.

Als im Jahre 1842 die ministerielle Verordnung über Communal- und Hospizarchive erschien, hatten wir schon bedeutenden Vorsprung gewonnen und konnten sogleich durch gedruckte Formulare den Maires die Inventarisirung ihrer Akten anivefehlen. Nach drei Jahren blieb nur eine kleine Zahl von Gemeinden im Rückstand. Das verhängnissvolle Jahr 1848 brachte leider anarchische Zustände mit sich; in vielen Lokalitäten wurden die Schriften und Bücher verschleudert, es musste von neuem an das Ergänzen der lückenhaften Sammlungen gedacht werden. Die gleiche Thatsache wiederholte sich theilweise in den letzten Kriegsjahren. So hatte auch der dreissigjährige Religionskrieg - nur in weit stärkerem Masse aufgerăumt. Vor 1648 finden sich auf dem Lande nur wenige Archivalien, welche die Agrarverhāltnisse betreffen.

Das Archiv des Strassburger Civiltribunals kam schon 1842 an 
die Reihe. Bei Eröffnung des Generalraths im Spätsommer wurde eine Bittschrift der Adrokaten vorgelegt mit der Anfrage: Was aus der im Jahr 1838 befürworteten Einordnung der Justizarchivalien geworden? es sei bereits eine, wenn auch unbedeutende Summe darauf angewiesen ... Die Petition setzte die Verwaltung in einige Verlegenheit; jene Summe ward, wie ich erfuhr, auf der Stelle zu anderen dringenden Zwecken verausgabt, und der Zustand der Justizarchivalien so kläglich, dass Niemand mehr die Hand an das chaotische Wesen legen wollte. Mir war bei anderwärtiger Beschäftigung sogar die Existenz der ungeordneten, in Gewölben, Speichern, Erdgeschossen zerstreuten Sammlung unbekannt geblieben. Nun wurde ich mitten in der Sitzung mit der Einsicht der verwitterten Akten und Register beauftragt und stattete im Laufe von wenig Tagen einen vorlāufigen Bericht $\mathrm{ab}$, der auf eine mehrjährige, materiell sehr beschwerliche Arbeit hindeutete. Der improvisirte Bericht wurde vom Generalrath günstig aufgenommen, die nöthigen Kredite auf der Stelle bewilligt und sofort mit dem undankbaren Geschäfte begonnen. Binnen drei Jahren war diese' Nebenarbeit beendigt und die geordneten Dokumente in drei dazu hergerichteten Sãlen untergebracht. Es bot die geläuterte Sammlung eine Reihenfolge wichtiger Prozesse, besonders aus der Revolutionszeit, dann viele in das ältere Gerichlswesen von Strassburg und Hagenau einschlagende Sachen. Das Feuer einer Augustnacht 1870 vernichtete diese Archivalien.

Einer der mir zugegebenen Arbeiter hatte wăhrend dem Sichten der vermoderten Akten gleich zu Anfang den Grund zu einem Nervenfieber gelegt und starb eines verfrühten Todes. Ich erwähne diesen Unfall, wenn auch schon mehr denn dreissig Jahre vergangen sind, um dem Einwurfe vorzubeugen, es sei solche obscure Arbeit gefahrlos. Noch jetzt erschüttert mich die Rückerinnerung.

Mit elsassischen und auswärtigen Kollegen kam ich hin und wieder schon in den ersten Jahren meines Amtes in Berührung. Der ausgezeichnete Gelehrte Mone, welcher Director des grossherzoglichen Karlsruher Archivs, besuchte mich zum ersten Male im Sommer 1843 auf längere Zeit; er notirte im alten Archive die auf badische Grundsteuer bezüglichen Pergamente und begehrte deren Auslieferung gegen mehrfache für den Unterrhein nicht unwichtige Schriften. Seinem Wunsche wurde erst viel später gewillfahrt. Herr Sers war Gesuchen dieser Art durchaus ungünstig; er legte denselben mit Unrecht andere Zwecke unter. - Jedenfalls erfreute ich mich der Ge- 
genwart des encyklopädischen, seit einem Vierteljahrhundert berühmten Archivars und verdankte ihm mannigfache Belehrung und Aufmunterung. Dienste zu leisten war er stets bereit; ich bewahre dem hochverdienten Ehrenmann ein dankbares Andenken.

Ein benachbarter Kollege, Louis Hugot, Stadtarchivar von Kolmar, besuchte mich kurze Zeit nach meiner Installirung. Ein eigenthümlicher, origineller Charakter, etwas räthselhaft. Er erzeigte sich mir als das seltsame Exemplar eines leidenschaftlichen Sammlers. der bei allzu weit gestecktem Ziele die Gegenwart aus den Augen verliert und mit den besten Absichten, bei strengster Ehrlichkeit, dem Tadel auswärts Stehender einige Blössen bietet. Hugot ist einer der Hauptgründer des Museums von Kolmar; in dieser Beziehung bleibt sein Lob ungeschmälert. Ich habe bei anderer Gelegenheit seine Verdienste um diese Lokalschöpfung auseinandergesetzt und berichtet, wie er opferfähige Gönner, z. B. Herrn - Fritz Hartmann, den Pair von Frankreich, für seine Pläne einzunehmen verstand. Dass die Gemäldegallerie der alten elsassischen Malerschule in die schönen Rãume des ehemaligen Klosters Unterlinden übergeführt, dass andere Sammlungen - die chinesische, die zansibarische u. a. - damit verbunden wurden, ist grösstentheils Hugot's Werk. Dorthin barg er die gallo-keltischen Alterthümer, die er in Nacht und Nebel an der lothringischen Gränze auf einen Ochsenkarren lud und beinahe verstohlen nach Kolmar brachte. Mit naiver Selbstgenugthuung erzählte er diesen antiquarischen Feldzug. Die Stadtbibliothek von Kolmar, deren Incunabeln und Manuskripte, vermehrte er bedeutend durch Ankäufe, Austausch und freiwillig dargebotene Gaben.

Mit mir suchte er anzuknüpfen, aus angebornem Trieb zu kollegialischer Freundlichkeit, und weil er mich für seinen Plan der Ausbeutung und wissenschattlichen Benützung des Gemeindearchives von Hagenau gewinnen wollte. Es war dasselbe reich an kaiserlichen Urkunden und geschichtlichen Dokumenten aller Art. Zur Herausgabe eines Codex diplomaticus hatte er sich mit dem Maire von Hagenau verstanden: ein Kontrakt lag bereit; der Druck sollte in einen bestimmten, ziemlich engbegränzten Zeitraum beendet sein; allein die Zustimmung des Präfekten, seine Unterschrift, war noch keineswegs gesichert.

Hugot wendete sich an mich. Der Bescheid des Präfekten lautete erst ausweichend, dann abschlägig. Meine Unterhandlung mit dem Departementschef artete aus in halbkomische Szenen. Ich 
stellte Herm Sers mit all mir zu Gebote stehender Eindringlichkeit vor, dass nıeine' Beschäftigung in dem mil zugewiesenen Archiv auf Jahre hinaus all meine Kräfte in Anspruch nehme, dass meine Pflicht mir gebiete einem gewiegten Kollegen, einem Schüler der Ecole des Chartes (!) die Mittel zur Veröffentlichung der geschichtlichen Schätze Hagenau's zu schaffen.

„Lassen Sie niemals, « erwiderte mir der Präfekt abweisend, vlassen Sie nie einen Fremden Fuss fassen in Ihrer Domäne; kein auswärtiger Archivar soll sich herüber schleichen über den Landgraben zwischen Ober- und Unter-Elsass. Sie haben jetzt nicht Zeit, behaupten Sie; ich lasse es gelten: sagen sie Ihrem werthen Collegen: ich behalte mir diese Arbeit vor auf spātere Tage.c

»Er wird mir's nicht glauben.« — „Glauben oder nicht, gleichviel!« Ich bestand hartnäckig auf meiner Empfehlung.

»Sie wollen es durchaus; nun, ich setze meine Unterschrift unter den Kontrakt; Sie werden es bereuen.\&

Ich bereute nicht im Geringsten meine Dienstleistung; aber Louis Hugot kam durch sein Unternehmen später in grosse Verlegenheit. Er konnte die zugestandene Frist nicht einhalten, seinem geschriebenen und mündlichen Versprechen nicht nachkommen, die Kredite waren aufgezehrt, bevor die weitlāufige, gewissenhafte, schön durchgeführte Arbeit völlig zu Ende; sie zog sich hin bis in die mittleren Jahre des zweiten Kaiserreichs. Da versagte einem Nachfolger des früheren Maire's die Geduld; er drang in die Ablieferung der Arbeit und die Herausgabe der Pergamente: Hugot zögerte; zweimal erbat und erhielt ich Aufschub; der Präfekt Herr Migneret, wic früher Herr Louis Sers, belächelte mein Zutrauen. Zuletzt erging vom betheiligten Maire ein Drohen mit gerichtlicher Belangung. Eingeschüchtert brachte der Kolmarer Stadtarchivar seine histen nach Hagenau. Gleiche Szenen wiederholten sich einige Jahre später mit unbedeutenden Archivalien der Stadt Türkheim, die in einem Umzuge von Hugot verlegt worden. Einen unmässigen Kostenersatz wussten die gerichtlich ernannten Experten, der verstorbene Bibliothekar von Strassburg (Prof. Jung), der Archivar von Pruntrutt (Trouillat) und der Archivar des Niederrheins, abzurnindern. Hugots Gesundbeit war durch den Aerger und die Unruhe erschüttert; er ging bald darauf mit Tode $a b$, nachdem die vermissten Dokumente sich in einem Winkel wieder vorgefunden. - Der verdienstvolle Forscher, Sammler und Antiquar, der liebenswürdige Freund und Kollege 
hatte sich selbst seine letzten Tage verkümmert. und sein Andenken wurde noch durch den harten Ausspruch eines Generalinspektors der Archive bemäkelt: „Hugot, « so liess sich der Hochgestellte aus. shabe seiner Pflicht als Stadtarchivar nicht genügt.< Freilich hatte der Arme, von Sammeleifer aufgerieben, sich nicht viel um die seelenlose Inventarisirung nach vorgeschriebenem Formular, gleich anderen. bereitwillig entschlossen.

Von verschiedenen Punkten Frankreichs und Deutschlands besuchten bereits in den ersten Jahren meiner Amtsführung mehrere Gelehrte das Elsässische Hauptarchiv und nahmen Einsicht in die theilweise verfertigten Inventare. Unter diese ersten Besucher zähle ich Dom Pitra (den späteren Kardinal Pitra), der den Weg, so ich eingeschlagen, zu beloben geruhte, wie ich mir denn, von allem Anfange an, ein streng objektives Verfahren zur Pflicht gemacht, und in unsrer von konfessionellen Zwistigkeiten aufgewühlten Provin\% unverbrüchlich die historische Mittellinie einhielt. Es sollte mir etwa zehn oder zwölf Jahre später diese selbstverständliche Unpartheilichkeit zu Gute kommen; die unglaublichen Zwistigkeiten über die protestantischen Stiftungen von St. Thomä übten eine Rückwirkung bis in die finstern Räume des Archivs; der Departementalarchivar hatte gan\% unsinnige Verdächtigungen $\mathrm{zu}$ bestehen, und noch unter der Verwaltung des sehr genässigten und vermittelnden Präfekten Migneret durchstöberte der Vertraute einer sehr einflussreichen geistlichen Gesellschaft meine vorgerückten Inventare, deren Redaktion er indess regelrecht, und jedes unliebsamen Ausdruckes bar und ledig zu erklären sich bemüssigt fand.

Ich hatte mit fieberhaftem Eifer den Vorschriften des Ministeriums des Innern über Klassificirung und Analyse des Departementalarchirs nachztkommen mich bemüht. Vom Ende des Jahres 1839 bis 1844 war eine Reihe von trefflichen, mustergültigen Arrêtés und Rundschreiben erschienen, welche dem Arbeiter eine nützliche Handhabe boten, und für ganz Frankreich eine nur etwas allzuschroffe Gleichförmigkeit anordneten. Bis in die kleinsten Einzelheiten wurden die Verpflichtungen der Präfekten, der Generalräthe, der Archivare geregelt, und in den meisten Departements bereitwilligst Hand an das umfassende Werk der Sichtung und des Verzeichnens aller aufgehăuften historischen, bis zum Jahr 1790 reichenden Schätze gelegt. Für alte und moderne Skripturen waren rationelle Formulare vorgesehrieben, die Arbeitsmethode, die Eventualităt des Verkaufs werth- 
loser Papiere vorgezeichnet; für das persönliche Loos der Archivbeamten und deren Pensionirung Vorkehrung getroffen. Es liess dieses zugleich reformatorische und halb legislatorische Verfahren wenig zu wünschen übrig. Erst später, einige Jahre nach der Februarrevolution erfolgte ein pedantischer Umschlag, es war als ob die Bureaux des Ministeriums ihren massgebenden Einfluss wieder in frische Erinnerung und die nur halbwegs vertheidigten Provinzialbeamten zur Verzweiflung bringen wollten. - Doch ich eile einem fatalen Zeitpunkte voraus; er trat ein, bei der definitiven Abfassung der Inventare, besonders der kurzgefassten Inventaires sommaires und deren Auslieferung zum Drucke. - Diese unsăglich sinnwidrige Plackerei darf nicht zur Ungerechtigkeit verleiten gegen das ursprüngliche Programm dieser archivalischen Arbeit. Theorie und Absicht waren goldwerth, die endgültige Ausführung der gewissenhaften Beamten, die sich dem Willen der Centralverwaltung unterwarfen, war eine mit nichts vergleichbare Geduldprobe. Dafür liefert die beibehaltene Korrespondenz unwiderlegliche Belege.

Unter die frūheren illustren Besucher des Archivs zähle ich Herrn Giraud, Mitglied des Instituts, der als Inspektor der Rechtsschulen nach Strassburg kam, und beiläufig auf dem Archive sich umsah. Der grundgelehrte Jurist und Forscher nahm Einsicht in die gedruckten >Rapporte๔, die ich seit 1840 jāhrlich dem Präfekten vorgelegt und stand nicht an, sie so wie die schon vorgeschrittenen Inventare zu beloben; er ermunterte mich fortzufahren auf dem eingeschlagenen Wege.

Solche günstige Aeusserungen waren durchaus nicht überflüssig, denn bereits unter der wohlwollenden Verwaltung des Herrn Sers wurden mir peinliche Erfahrungen zu Theil. So beschied man mich einmal im Laufe des Jahres 1846 in das untere Geschoss des Archivs; ich fand dort den Prāfekten und eine aus etwa acht oder zehn Mitgliedern bestehende $\rightarrow$ Commission mixte . Ich erkannte darunter Munizipalräthe und Architekten. Man bedeutete mir, dass ein Theil der Räumlichkeit für Versteigerungen und andere Zwecke bestimmt sei, und mir die innenliegenden Skripturen auf die Speicher zu übertragen sofort obliege. Auf meine obligate, gewissenhafte, leidenschaftliche Einwendung wurde nicht geachtet; mein Gönner verkündete mir eine bestimmte Frist; in wenig Tagen war die Ausrāumung bewerkstelligt. Damit begann der erste Einbruch in die Unverletzlichkeit des Departementalarchivs, ein Verfahren, das sich unter einem 
späteren kaiserlichen Nachfolger des Herrn Sers zweimal in weit grösserem Massstabe wiederholte. Mit diesem Unfug kamen die noch ungeordneten Akten der ehemaligen weltlichen Herrschaften in": Gedränge. Die Speicher wurden besonders für die Kommunalrechnungen zugerichtet, nach und nach schwoll aber die Fluth dieser unerlāsslichen Belege, und erreichte zuletzt die höchsten Dachziegel: im Sommer bei einer Senegalshitze, im Winter bei sibirischer Kālte fanden die Recherchen statt; mit welchem Schaden für die Gesundheit der betreffenden Arbeiter, ist leicht zu ermessen.

Mit dem verhāngnissvollen Jahre 1848 eröffnete sich für mich eine ungeahnte, in manchen Sinn erwünschte Thätigkeit; allein die unausbleiblichen Folgen einer Doppelstellung blieben nicht aus, und erprobten, mir zum Nachtheil, ein altes vulgäres Sprichwort: »dass man nicht zwei Herren zugleich dienen könne. Seit meinem Eintritt in die Präfektur hatle ich mich, con amore, mit Kultusangelegenheiten befasst, die Organisation der protestantischen Kirche im Elsass studirt; durch eine innere Privatrevolution im protestantischen Direktorium wurde ich zu aktiver Mitwirkung gezogen. Ich spiegelte mir ein erwünschtes, nützliches Eingreifen vor, bereitete mir jedoch binnen wenig Jahren unsäglichen Verdruss. Das nur aus fünf Mitgliedern bestehende Direktorium war veraltet; durch Krankheit, Abwesenheit einiger Persönlichkeiten auf ein Nichts zusammengeschmolzen. Die stãdtischen Consistorien verlangten eine ausgedehntere Vertretung der kirchlichen Interessen, eine grössere Zulassung des Laienelements im Oberconsistorium und setzten proprio motu, durch die anarchische Atmosphäre in Paris begünstigt und ermuthigt, einen VerwaltungsAusschuss von zehn Mitgliedern ein, der sich mit der Revision des seit dem Anfange des neunzehnten Jahrhunderts bestehenden organischen Gesetzes befassen sollte. Diese Commission ernannte mich zu ihrem Schrifttührer.

Der bisherige Generalsekretär des Direktoriums, ein gewiegter Geschäftsmann, blieb für Laufendes im Amte; allein er hatte persönliche Gegner in dem neuen freisinnigen Comité, man beschnitt im Laufe des Jahres 1849 seinen Gelialt, er fühlte sich beleidigt und gab, so sehr ich ihm aufrichtig zuredete, den momentanen Sturm zu überdauern, seine Entlassung.

Man bot mir die Stelle an. Ich besprach mich mit dem damaligen republikanischen Präfekten, Herrn Renauldon, der bereitwillig seine Erlaubniss dazu hergab. Unter seinem ersten Nachfolger, 
Herrn Chanal, kam es nicht zur geringsten Reibung zwischen dell zwei Behörden; anders stellte sich die Sache etwa zwei Jahre nach seinem Abtreten. Es wurden in Strassburg und in Paris formelle Angriffe gegen die Stiftungen von St. Thomä geplant. Da ich, zwar nur als passiver, untergeordneter Skribent mit der vollen Wucht meiner Ueberzeugungstreue dagegen einkam, missfiel dem jugendlich heftigen, ultramontanen Departementschef die Stellung eines Beamten, der sich in zwei nunmehr feindlichen Lagern befand. Er war dazı von seinem Standpunkt aus vollauf berechtigt, so sehr ich eine Zeitlang durch ein naiv aufrichtiges Behaben an den Tag legte, wie sehr ich über jeden Verdacht eines partheiischen Eingreifens, oder des herüber und hinüber Schwankens stände. Eine Zeitlang war sogar dem Zweifelnden meine Doppelstellung als eine vermittelnde erwünscht geblieben.

Allein die eigentliche Stunde der Krisis schlug im Laufe des Jahres 1854. Dem eindringlichen Ansinnen meiner Glaubensgenossen zuwider, entschloss ich mich, dem Archiv ausschliesslich meine Kräfte zu weihen und mit verdoppelter Anstrengung dem vor vierzehn Jahren begonnenen Inhaltsverzeichniss wieder obzuliegen.

Ich schlug diesen Weg ein, nach reiflicher Ueberlegung; aber noch jetzt, ich darf es behaupten, mit wundem Herzen. Durch mein Verbleiben im Direktorium hätte ich wo nicht wolkenlose, doch relativ ruhige Tage für das hereinbrechende Alter gewonnen; durch mein Verweilen im Archiv ging ich einem beständigen Kanpfe mit den Pariser Bureaux entgegen, und beharrte in einer wahrlich oft undankbaren Danaidenarbeit.

Während den Wintermonaten 1854-1855 hatte mir der Präfekt zuvorkommend eine zur Erholung nöthige Frist gestattet. Er wurde im Mai nach Toulouse versetzt, und von Paris, in sämmtlichen Departementen, die Inventarisirung betrieben; •ich konnte und wollte nicht der Letzte sein in diesem Wettlauf nach einem obskuren, aber für die Betheiligten wichtigen Ziele. Die Lücken in meinel früheren Arbeit auszufüllen, griff ich thätig ein: deutlich vorgezeichnet hatte ich meinen Weg; ich wollte durchaus, in möglichster Zeitfrist, die ganze mir zugewiesene Sammlung bewältigen zu Nutz und Frommen auswärtiger und inländischer Forscher; einzelne Unrichtigkeiten, Uebereilungen mochten bei diesem Bestreben mit unterlaufen, in der Hauptsache bin ich noch heutigen Tags, das Rechte gewählt zu haben, überzeugt. 
In Paris griff man mir nicht unter die Arme. Mit pedantischer Strenge wurde ich auf jedem Schritt und Tritt gehemmt. Zuförderst konnte ich nur mit Mühe zum Verständniss der bureaukratischen Diktatoren bringen, dass die Elsassische Geschichte eine ganz eigenthümliche, von allen Theilen des innern Frankreichs total verschiedene sei. Die sogenannte Landvogtei von Hagenau z. B., schlug in mehrere der vorgeschriebenen Serien oder Fächer des offiziellen Programms. Der Landvogt hatte zugleich militärische, gerichtliche, finanzielle, administrative Befugnisse. Nicht spalten, nicht auseinanderreissen konnte man die auf seine Verwaltung bezüglichen Schriften; für die eine oder die andere Serie musste man sich entscheiden. Nur nach langweiligem Auseinandersetzen, nach unerquicklichen Debatten, nach dem Unterbreiten einer von mir gewissenhaft verfassten geschichtlichen Monographie über die verwickëlten Verhältnisse ${ }^{1}$ ) wurden solche unumgānglichen Streitpunkte beigelegt oder erobert, die Zugeständnisse wie ein Gnadenakt betrachtet, und der eigensinnige Deutsche gleich einem widerhaarigen Gegner, einem ungelehrigen Schüler, behandelt. IIl est fou, il est au moins monomane, votre archiviste«, sagte man dem wohlgesinnten Präfekten. Der Provinzialbeamte musste oft jeder selbstberechtigten Ansicht entsagen, nur froh sein, wenn er hinreichendes Feld gewann, seiner Pflicht genug zu thun. Widersinnige Versetzung ganzer geschichtlicher Complexe wurden von obenher erzwungen. So kam eine mit »Collège de Molsheim " harmlos überschriebene Gruppe, aus den Serien des geistlichen Archivs herausgerissen, in das Civilarchiv zu stehen, weil dieselbe in den Augen der entscheidenden Beamten als "Collège « in das öffentliche Unterrichtswesen gehöre. Benannte Gruppe enthielt aber durchweg historische, geistliche, auf das Sankt Marienhospital in Molsheim bezügliche Dokumente und diese mittelaltrigen Urkunden waren im Jahre 1580 den Jesuiten als Erben jenes lokalen Vereins verblieben. Keine Einrede half.

Einem Laien muss eine solche Debatte unerquicklich, fast lächerlich erscheinen. Für den betheiligten Archivar ist oder war dies nicht ganz derselbe Fall. Es brachten solche gezwungene, willkührliche Ueberführungen eine unberechenbare Störung in die tägliche Arbeit. Das gesammte ältere, geschichtliche Archiv ist in zwei

1) Rapport au prèfet du bas Rhin sur la préfecture de Haguenau. Strassburb 1857. Ein Bändchen in $8^{\circ}$. 
H a uptabschnitte, das Civil- und das geistliche Archiv geschieden. Jede dieser Abtheilungen mit ihren sogenannten Fonds oder einzelnen Complexen war nach Vorschrift durch eine ununterbrochene Zifferzahl aller Urkunden und Bände versehen. Zieht man nun in Erwägung, dass sich eine solche Folgenreihe in die Tausende beziffert und dass durch ein Einschieben sich die ganze Numerirung verschiebt, die veränderten Namen auf Umschlāge und Faszikel in die Inventare eingetragen werden müssen, da lässt sich leicht ermessen, wie gewissenhafte Beamte zur Verzweiflung getrieben wurden.

War denn kein Rekurs, keine Abhilfe möglich? In der für mich arbeitreichsten Zeit, etwa von 1855-1861, nahm der intelligente und wohlgewogene Chef des Departements meine Klagen an, gab mir an Ort und Stelle, nach abgegebener Erklärung, völlig Rech1; aber der Endausspruch lautete immer: 'Halten Sie um jeden Preis Frieden mit den Bureaux! Ich bevollmăchtige Sie, ihren Protest in einem Plakat an die betroffene Serie zu heften. - - Das klang dann wieder wie eine halbe Ironie. Liebenswürdig zuvorkommend war in jener Epoche ein Generalinspektor, der mich mehrmals gewissenhaft besuchte und zu allem Anfang treffliche Anweisungen über die in Paris verlangte Arbeitsmethode gab. Sein Name klang deutsch: Herr von Stadler; allein er war ein Stockfranzose und bewährte sich, neben seinem offiziellen Amte, als Literat und historischer Forscher. Rlagte ich ihm meine Noth, da gab er alle Einwürfe gegen die Schroffheit der Centralbehörde zu; doch stimmte am Ende sein Rath genau mit dem Präfekten überein: sHalten Sie um jeden Preis Frieden mit den Bureaux.*

Wie beleidigend das Verfahren dieser autokratischen Pariser Bureaux, erhellt aus einer Thatsache, die sich mehrmal in der ersten Zeit der von mir unternommenen Redaktion der Inventare wiederholte. - Die am Rande der Hefte angebrachten Vorschriften widersprachen sich oft in kleinen Zwischenräumen, je nachdem die Bekrittelung von dem oder jenem Unterbeamten ausgieng; - denn ich würde mir auch jetzt, nach vielen Jahren, nicht erlauben, solche dem verdienstrollen Chef des Archives, Herrn von Champollion-Figeac, den Neffen des unsterblichen Egyptologen, aufzubürden. - Nun, dieser schreiende empörende Missbrauch des Examinatorenrechtes hörte doch an Ende auf.

Neuen Ungelegenheiten ging ich mit der Abfassung der sogenannten Inventaires sommaires und deren Beförderung zum Druck 
entgegen. Man hatte für dieses weitläufige Unternehmen und desitn Uebernahme auf eine Pariser Buchdruckerfirma, Dupont, dessen Chef zugleich in der Deputirtenkammer sass, hingewiesen; in Strassburg war die Präfektur nicht gesonnen, der trefflichen Firma BergerLevrault diese Arbeit zu entziehen. Die eigenmächtigen Pariser horrekturen verschlangen systematisch eine köstliche Zeit, der gemassregelte Text konnte immer nur nach langem Hin- und Herziehen die Examinatoren befriedigen; eine gewisse Zeilenzahl durfte in den einzelnen Artikeln nicht überschritten werden. Des Zusammen- und Auseinanderziehens war kein Ende. Selbst dem mit Archivwesen nicht vertrauten Laien lässt sich leicht begreiflich machen, welch ein barokes Aussehen dergleichen chablonenhaft rerfasste Artikel oft erhalten. - Interessante, reichhaltige Materien mussten abgekürzt, gleichgültige, zwar nicht ausführlich behandelt, doch jedenfalls berülı't werden; denn nicht nur die Zeilen, auch der numerische Inhalt dieser Absătze blieb fesıgesetzt und beschränkt. Bereits in der Abfassung des endgültigen analytischen Inventars (1854-1861) hatte sich diese Unbequemlichkeit für den Redaktor erwiesen. - Immerhin mag das Ganze, - da ich mir angelegen sein liess, so weit es angewiesener Kredit und Bevormundung der hauptstädtischen Bureaux gestatteten, voranzuschreiten, - als ein nutzbarer Ueberblick gelten. Nur konnte ich, nachdem mir durch Austausch dirInventaires sommaires anderer Departemente zukamen, wohl beinerken, dass bevorzugte oder widerspenstige Kollegen sich dem strengen Kommando durchaus nicht unterwarfen und ihre erste eigene Redaktion beibehielten. Die trostlose Arbeit zog sich, - nach Massgabe der dazu ausgeworfenen Kredite - während dem letzten Decennium des Kaiserreichs hin, und wurde erst unter der deutschen Verwaltung noch in französischem Texte geschlossen.

In dieser letzten Periode des französischen Regimes vollzog sich für das Departementalarchiv ein sehr erwünschter, aber doch sehr beschwerlicher Umzug. Seit zehn oder zwölf Jahren hatte sich, trot\% öffentlicher Versteigerungen, der Vorrath bedenklich angehäuft; er war wohl, seit meinem Eintritt ins Amt, auf das Drei- oder Vielfache gestiegen; sogar das ältere Archiv war in immerwährendem Zuwachs begriffen; nach Beendigung des grossen analytischen Inventars kam u. a. noch Zufluss aus den Tribunalen von Weissenburg und Zabern. Im Jahre 1857 hatte man dem Archivar ausserhalb des Hauptgebäudes eine feuchte, ehemalige Stallung zugestanden; 
sehr bald war sie aufgebraucht und angefüllt. - Herr Migneret kaufte, im Namen der Verwaltung, ein ehemaliges, südlich ron der Präfektur gelegenes Tabaksmagazin, eine nicht freistehende Rāumlichkeit; allein die innern Gelasse erwiesen sich bedeutend grösser, als das bisherige Archiv deren zu bieten hatte und im Sinne des Präfekten solte das Ganze zur ausschliesslichen Benützung dem Archivar überantwortet werden. Auf einige Decennien hinaus schien wenigstens die Aufnahmsfähigkeit gesichert. - Der Nachfolger des Herrn Migneret entwarf andere Pläne. Sobald die Gebāulichkeit, dem Kaufkontrakt zufolge, verfügbar geworden (1866), beschloss Herr Baron Pron, gegen jede Einrede gewappnet, den Präfekturrath mit dessen Tribunal, den Architekten des Departements, den Wegebaudirektor mit ihren sämmtlichen Bureaux dorthin unter Dach und Fach zu bringen. Vorläufig waren schon, auf höheren Befehl, ex abrupto, die ausserarchivalischen Rāume geleert und die zahllosen Akten in den Gängen des alten Archivs binnen wenig Tagen aufgespeichert. - Der definitive Umzug begann in den Frühlingsmonaten 1867, bevor die geringste Vorkehrung für Repositorien im neuen "Magazin « getroffen, während Schreiner, Zimmerleute, Maurer noch ihr Wesen trieben und die Bureaux mit feuchten Gypswänden zum Willkomm ihre Thüre öffneten. Es war eine trostlose Zeit. Ein unbiegsamer Charakter hatte diese unsinnige Eile befohlen. Es widersteht mir durchaus, in das Einzelne weiter einzugehen und einem ehemaligen Obern, einem geistreichen Manne, von dessen blendenden Eigenschaften ich nichts abmarkten will, im Interesse todter Papiere, einen unliebsamen Nachruf zu halten.

Als providentielles Gegengewicht darf ich es wohl ansehen, dass fast um dieselbe Zeit, nach kaum nothdürftig vollzogenem Einräumen, mein erstes Begegnen mit dem bayerischen Reichsarchivdirektor, Franz von Löher, fiel. Er kam während der Sommermonate 1867 nach Strassburg, zum Anknüpfen einer Unterhandlung über gegenseitigen Austausch von Archivalien; er, von bayerischer Seite, die Auslieferung zahlreicher historischer Rappoltsteinischer Urkunden und dagegen aus dem Departementalarchiv eine ebenfalls ansebnliche Folgenreihe von Urkunden aus der ehemaligen Grafschaft Sponheim wünschend. Diese Pergamente hatten für das Wittelbachische Fürstenhaus ein Kabinets- und Familieninteresse.

Es dehnten sic -die benöthigten Vorbesprechungen mit dem Präfekten, dem Generalrath, dem Ministerium des Innern und der 
auswärtigen Angelegenheiten auf Jahreslänge aus. Im Sommer $186 \mathrm{~S}$ kam Lüher zum zweitenmal hierher und der Austausch wurde offziell vollzogen. Die an mich hinterlassenen Dokumente sandte ich pflichtgemäss sogleich an das Archiv des Oberrheins, denn es lag die ehemalige Rappoltsteinische Herrschaft in jenem Bezirke; ich wollte sofort den Beweis führen, dass ich nicht für eigene literarische Zwecke die Sache angelegentlich betrieb.

Das erwünschteste Resultat dieses höchst complicirten Geschäfts war für mich die erworbene Freundschaft Herrn von Löher's; er hatte mehr als ich, mit Beiziehung des Pfarrer Lehmann von Nussdorf, das Ganze betrieben und mit seiner jugendlichen Arbeitskraft mir, dem Alternden, viele Beschwerlichkeiten erspart. Es waren mir von München aus auch mehrfache Auszeichnungen beschieden, für die ich noch jetzt dem neuerworbenen Freunde und unbekannten Gönnern innigen Dank schulde.

Die drohende Zukunft hatte ich mit Löher frank und frei damals schon besprochen; aber das Unglück sollte noch früher und schwerer hereinbrechen, als mein angeborner Pessimismus befürchtete. Nicht unerwartet trafen mich die Hiobsposten der benachbarten Schlachtfelder vom 4. und 6. August 1870. Ohne die Instruktionen des Präfekten abzuwarten, flücntete ich die kostbarsten Archivalien in eiserne Behältnisse des unter dem Archiv befindlichen Geschosses. Allein an das Ausräumen des ganzen Departementalarchives war nicht mehr 7.u denken, um so weniger, da mit oberer Genehmigung gegen meinen unbeachteten Protest die Intendanz mehrere mit Weingeist gefültte Fässer in die unterirdischen Gewölbe bergen liess. Auch andere Verwaltungen hinterlegten dort ihre Register und Papiere. Das Bombardement zerstörte gleich in den ersten Tagen unsere Bureaux und die Speicher, jedoch ohne zu zünden. An irgend eine Arbeit in den verheerten und stündlich bedrohten Räumen war nicht zu denken. - Mir wurde nicht gestattet, mich in den untern Räumen des Archivs einzurichten; in der Folge der sich überstürzenden Unfälle, besonders in der Nacht des Präfekturbrandes, rettete man dorthin das Mobiliar und fanden Obdachlose und Verwundete eine temporäre Unterkunft, man behauptet sogar, es habe ein Sterbefall sich dort ereignet. Der Chef der Vicinalwege aber wohnte sich ein so gut es ging mit Frau und extemporirter Küche. Ein wahres Wunder, dass nicht grössere Lücken in den Akten selbst entstanden. In den allerletzten Tagen vor der Kapitulation rāumte mein 
Adjunkt nit Lebensgefahr und mit Hülfe zahlreicher Arbeiter die obersten Stockwerke. Um dieselbe Zeit hatte ich mich, aufgerieben durch sechswöchentliches Wachen, mit einem von Freunden zugeschickten sichern Geleit nach Baden geflüchtet, wo ich zerrüttet am 23. September ankam. Vier Tage nachher ging Strassburg über, und ich sãumte nicht, nach kurzer $\mathrm{Zwischenruhe,} \mathrm{den} \mathrm{6.} \mathrm{Oktober}$ mich den deutschen Behörden zur Verfügung zu stellen.

Noch war Alles in der grössten Unordnung; es erforderte keine geringe Arbeit, nach oberflāchlicher Ausbesserung der alten Rāume die geflüchteten Kisten, die geborgenen Register und Bücher, den beinah ganzen archivalischen Apparat wieder in die ehemalige Stellung $z u$ bringen. Die Kommandantur gab dazu bereitwilligst die Mittel an die Hand; nicht weniger als vierzig Soldaten - Landwehrmānner - vollbrachten, bei strenger Winterkälte, unter des Adjunkten Fastinger unermüdlicher Anleitung das erste, Unentbehrlichste; nach und nach konnte man die Arbeiterzahl auf fünf beschränken. Ich denke an die Hülfeleistung dieser intelligenten Kumpane mit Freuden zurück; in Laufe Januars gingen sie nach Belfort $a b$; ich hoffe sehnlichst, dass sie im hohen Norden unversehrt ihren Angehörigen wiedergeschenkt sind.

Manches bleibt für die künftige Unterbringung des Archivs zu wünschen übrig. Die jetzigen Räume sind bei immer mehr sich anhāufendem Stoff total ungenügend; die Beamten sehen sich befangen in täglicher Verlegenheit; sie mussten einem elementaren geschäftlichen Prinzip entsagen; die gleichartigen Materien können sie nicht mehr, wie früher, in fortlaufenden Repositorien unterbringen.

Zurückzukehren ist für's erste zur Idee des französischen Präfekten Migneret, der beim Ankaufe der jetzigen Gebäulichkeit die Ueberlieferung derselben, in ihrer Totalităt, an den Archivdienst beschlossen. Diesem augenscheinlichen Erforderniss stellen sich leider grosse doch nicht unüberwindliche - Schwierigkeiten entgegen. Im jetzigen Zustande der Stadt und Festung Strassburg hält es schwer, für die Beamten eines Theils des Bezirks, welche gastlich im Archivgebäude aufgenommen wurden, andere Räumlichkeiten aufzufinden. Man vertröstet sich auf die bevorstehende Erweiterung der Stadt. Dann wird wohl der Bau eines neuen Archivs, auf völlig freistehendem Terrain befürwortet; durch dicht anstossende und gegenüberliegende Hăuser bleibt das jetzige bei jedem ausbrechenden Feuer gefăhrdet; die schon so ungünstigen Verhältnisse gestalten sich dann noch un- 
günstiger. Mit dem künftigen Distriktsarchiv wäre wohl das geschichtlich höchst bedeutende Stadtarchiv unter demselben Dache unterzubringen; denn in seiner jetzigen Lage ist auch das letztere, wie seine zwanzigfach umfangsreichere Schwestersammlung, denselben Gefahren ausgesetzt.

Solche weitausstehenden Pläne gehören indess für den bekümmerten gealterten Archivar in das Reich der pia desideria, wofür sein persönlicher Einfluss nicht um einen Gran schwer in die Wagschale fällt.

Bei diesen rasch und abgebrochen über mein Amtsleben hineilenden Erinnerungen habe ich den Inhalt der mir anvertrauten Archivalien ganz oder fast ganz unberücksichtigt bei Seite gelassen. Ich erlaube mir nun, auch hier eine oberflächliche Rundschau zu halten. Es findet sich wohl einmal, für mich oder meinen Nachfolger, Zeit und Gelegenheit, mehr in's Einzelne einzugehen und dabei die vorliegenden Inventare zu benützen.

Bereits oben machte ich auf die schon in der Natur der Sache begründeten Hauptabtheilungen aufmerksam. Wir betreten zuerst den Raum der weltlichen, der Civilarchive. Das Programm des Ministers des Innern hatte vorerst das für Frankreich kritische Jahr 1790 als Scheidepunkt angenommen; bis dorthin und nicht weiter sollte sich die Repertorisirung der geschichtlichen Dokumente erstrecken. Mit dem Revolutionsdecennium war ein neuer Zeitabschnitt festgesetzt, und von dort an keine Linie mehr zwischen weltlichem und geistlichem Archiv gezogen. Von 1800 an bis in die laufenden Jahre fiel alles in die modernen Cartons.

Für Unterelsass gehört in dies Civilarchiv die Reihenfolge der ehemaligen Landvogtei Hagenau, der französischen Intendance d'Alsace, der deutschen unter französischer Oberherrlichkeit verbliebenen deutschen Herrschaften: von Hanau-Lichtenberg, d. h. das Darmstädtische Gebiet; die Zweibrückischen, d. h. churpfälzischen Gebietstheile; die Herrschaft Oberbronn, den Leiningen zustāndig; das Unterelsassische Adelsdirektorium;

und einige, durch nicht aufgeklärte Zufälle in dem Bereich des Distriktsarchiv zurückgelassene Sammlungen; z. B. die Mömpelgarder Akten; der Grafschaft Sponheim zugehörige geschichtliche Pergamente, mit Prozessakten, Kommunalangelegenheit, Forstwesen u. a. m. 
Unter diesen Rubriken nimnit für mich die Hanau-Lichtenbergische den ersten Rang ein. Leugnen will ich nicht, dass neben dem reichhaltigen, ausgedehnten Stoff, persönliche Beziehungen bestimmt einwirkten. Nicht allein die hohe Gestalt des Bischofs Konrad von Lichtenberg, vermuthlichen Beschützers Erwins, nicht allein die Brüder Ludwig und Jakob von Lichtenberg mit des Letzteren Konkubine, der als Hexe hingerichteten Barbara von Ottenheim, nicht allein die Hanauischen Grafen der Reformationszeit in ihrer Residenz von Buchsweiler und ihre Nachfolger, die Prinzen von Hessen-Darmstadt, zogen mich an, seit Jahren, unwiderstehlich ... Ein Beamter, ein elsassischer Verwalter dieser unter französischer Hoheit im Elsass begüterten Dynasten, war mir ein mütterlicher Grossohm, und bezahlte seine Treue, seine rührende Anhānglichkeit an seinen Herrn auf der Guillotine. In meiner frühesten Kindheit wurde ich vertraut mit dieser tragischen Familienszene; sie liess in meinem Gemüth unvertilgbare. Spuren zurück. Als ich später die lokale Geschichte bis in's Einzelne durchnahm, hob sich die Figur des schmählich Hingerichteten, Heinrich Rausch, des darmstädtischen Einnehmers, von dem Gewitter-Horizont ab, welcher die letzten Jahre der Darmslädter Prinzen im Elsass verfinsterte. Man verdenke mir's nicht, dass ich, mit ernsten Studien solche vielleicht egoistischen Erinnerungen verband; sie ermuthigten mich zur geistlödtenden Arbeit des Repertorisirens.

Bereits mit dem Jahr 1790 , vielleicht schon 1789 , waren die confidentiellen Privatdepeschen von Buchsweiler nach Darnstadt geflüchtet; die zurückgebliebenen Verwaltungsakten, die in Strassburg untergebracht wurden, enthalten indess in ihrem jetzigen $\mathrm{Be}$ stande viel Anziehendes und Belehrendes. Sie geben direkte und indirekte Auskunft über den Regierungsrath von Buchsweiler, dessen geistliche und weltliche Kollegien, ein kleiner Staat im Staate, d. h. eine Anomalie, ein fünftes Rad in der französischen Verwaltungsmaschine; doch mit hinreichender Selbstständigkeit ausgestattet zum Nutzen und Gedeihen der etwa hunderttausend in einem Dutzend Amteyen zerstreuten Einwohner.

Der blühende Ackerbau in diesen landgräflich Hanauischen Bezirken, d. h. in der Umgebung von Buchsweiler, Brumath, Westhofen, Strassburg, der Lichtenau sprang in die Augen; und der patriarchalische Charakter dieser Duodezverwaltung wurde nicht verwischt durch die Etikette, die sich in der nächsten Umgebung des 
regierenden Herrn, im Schloss zu Buchsweiler oder in darmstādtischen Hof zu Strassburg, festsetzte. Es waren eben nur angeerbte Formeln, wodurch der innere Werth der Persönlichkeiten und ihrer Regierungsmethode keinen Eintrag erlitt.

Was nun den eigentlichen Inhalt der Hanau-LichtenbergischDarmstādtischen Dokumente betrifft ${ }^{1}$ ), so ist deren Charakterisirung, wie man es nimmt, leicht oder schwer; sie umfassen die Totalitït des Lebens und Treibens einer Provinzialbehörde. Am zahlreichsten sind die Anlagen von Renten, die mannigfaltigen Schriften, die heulzutage Notariatsakten bilden. Zahlreich sind die Belege der öffentlichen Arbeiten, der Strassen- und Wasserbauten; zahlreich die Pergamente und Papiere, welche für die pittoresken Mühlen des mittleren Elsasses gleichsam zur fortlaufenden Privathistorie werden. Selbstverstāndlich treten die Namen der gräflichen Lehensherren vor Allen hervor; auch andre herrschaftliche Familien nehmen Rang und Stellung und bilden für die epwähnten Oberherren ein nicht zu verschmähendes Geleite. Zu mancher Dorfschaft, Geudertheim, Brumath z. B., wären kleine Monographien herauszuschreiben, und da man in Elsass für solche mikroskopische, bequeme Forschung vielen Sinn bewahrt, so mag dies mit der Zeit ausgeführt und dann in den unterschiedlichen Gemeindearchiven solche pietätrolle Erinnerungen ad aeternam rei memoriam hinterlegt werden.

In todten Akten nicht allein, nicht allein in den restaurirten Gebäulichkeiten der jetzigen Strassburger Bürgermeisterei ${ }^{8}$ ) wird das Andenken an die Darmstädter aufbewahrt. Die Orangerie in der Ruprechtsau verdankt dem Buchsweiler Schloss ihre hundertjährigen Goldäpfelbäume. Nie verlieren sich meine Schritte in diese würzreichen, balsamduftenden Alleen, dass nicht die Erinnerung an die herrschaftlichen Gärten der "Darmstădter « über mich kāme ${ }^{3}$ ).

Die herrliche, farbenreiche Archivgruppe der kaiserlichen Landvogtei von Hagenau bot mir ebenfalls persönliche Anziehungspunkte; aus dem historischen Gebiete dieser Verwaltung hohenstaufischer,

1) Etwva 170,000 Stūck.

2) Dem Darmstådter Hof.

5) S. o. meine histoire du Comté de Hanau-Lichtenberg. Strassburg 1858 in $8^{0}$. Dasselbe in meinen Oeuvres choisies Tome III p. 339 u. ff. -397 oder in den bulletins de la société pour la Conservation des monuments historique d'Alsace. Ire série. Tome III. p. 1 u. s. f. Meine Modernen Kultuszustände im Elsass, passim. 
luxemburgischer, slavischer, pfalzgräflicher, österreichischer Herren tauchten sie auf, in ganz eigner Beleuchtung. War mir doch die Silva sacra von Hagenau als die dichterische Domäne Gottfrieds von Strassburg und anderer hagenauischer Sānger an's Herz gewachsen; lockte mich doch die blosse Erinnerung an die'Barbarossische Schlossherrlichkeit auf einer Insel der Moder in ihren mysteriösen Bann! War doch der selige Hugot mein Introduktor in die Schätze des Kommunalarchivs gewesen! Neben ihm machte ein modester Arbeiter sich geltend, der sich an die vergilbten Blätter des ebenfalls an die Hohenstaufen hinaufreichenden Hospitalarchivs wagte und dieselben aus dem Staube zog. Wenker's, des Hospitalschreibers Figur, ist eine ungemein rührende... ein betagter, naiver Mann, der beinah ganz autodidaktisch das freiwillig unternommene archivalische Tagewerk angriff, fortführte, mir periodisch von der vorschreitenden Instandesetzung berichtete und erzählte, welchermassen er seinen kleinstädtischen erstaunten Kompatrioten über die grosse Vorzeit ihrer Heimath Auskunft ertheilte. - Der Name Wenker's ist patronimisch; er knüpft sich an patrizische und gelehrte Persönlichkeiten Strassburgs. Inwiefern der einfache Hagenauer Schreiber mit denselben zusammenhing, wüsste ich nicht zu sagen; jedenfalls schliesst er sich durch sein lokalpatriotisches Unternehmen ganz würdig an dieselben. Als man mir vor bald siebzehn Jahren seinen plötzlich erfolgten Tod ankündigte, fühlte ich mich tief ergriffen, denn selten ist eine so uneigennützige Erscheinung.

In den Kartons der ehemaligen Intendanz liegt noch für die heutige Verwaltung viel brauchbarer, oft unentbehrlicher Vorrath. Die historische Wichtigkeit des Verwaltungsmechanismus von Richelieu springt in die Augen. Hier wurde derselbe zum Werkzeug der mehr und mehr angebahnten Verschmelzung der Nationalitāten. Diese Bemerkung gilt vorzüglich den oberen Klassen der Städte, weniger oder gar nicht dem Lande. In Kolmar operirte überdies, in dieser Beziehung, der Appellhof; in Strassburg trug die einheimische Gelehrtenwelt dazu bei. Die Dokumente der Intendanz sind von durchgreifender Wichtigkeit für die öffentlichen Arbeiten, den Strassenund Wasserbau, den Kataster - die Bannplāne vieler Ortschaften finden sich vor u. s. f. Das Lehenswesen bildet einen merkwürdigen Abschnitt. Es erscheinen die einzelnen adligen Familien in ihrem Verhältniss zur Regierung, wenn sie um Erneuerung ihrer Lehen bei der Regierung einkommen und zu diesem Zwecke die benöthigten 
Titel einliefern. So greift diese Abtheilung sehr hoch in frühere historische Zeit hinauf; ein Umstand, der sich in dem Abschnitt des hohen Mūnsterstifts wiederholt, wo die Kandidatur für die Kanonikatswürde im fürstlichen Kollegium nur durch genealogische Belege anzubringen war. In diesen Bewerbungen kommen aber meist Fremdlāndische von deutscher und franzősischer Abstammung vor.

Der Empfang königlicher Hāupter oder fürstlicher Persönlichkeiten lässt ebenfalls in den offiziellen Papieren der Intendanz Spuren zurück. Welch trübe Aussichten veranlasst doch Maria Antoinettens Durchzug! Wie vergegenwärtigt der mit Goethescher Literatur Vertraute sich dabei unwillkürlich die ahnungsvollen Gobelins auf der Rheininsel!

Die Reihenfolge der Intendanten von de Lagrange ab bis auf La Galaizière ist mehr oder weniger in dieser Archivgruppe vertreten. Interessant und lehrreich ist eine im Jahr 1866 unter der Verwaltung des Präfekten Baron Pron angekaufte Korrespondenz des Intendanten d'Angervilliers (1716-1724) mit den Päriser Behörden über die verschiedenen Verwaltungszweige des Elsasses und eine damit zusammenhăngende Serie von ausführlichen Mémoires, die aus späterer Zeit (vermuthlich von 1730-1751) stammen. Sie berichten über die Zustānde der Klerisei, des Adels; der Magistratur, des Kriegswesens, der Finanzen, des Forstwesens, des Handels. Auf den berüchtigten Prozess Klinglin bezieht sich ein konfidentielles Schreiben, vermuthlich aus dem Jahre 1751.

Schreiber dieser Zeilen übersendete an das Ministerium des öffentlichen Unterrichts, durch Vermittlung des Rektors der Akademie von Strassburg, im Laufe des ersten Semesters von 1870 eine sorgfältige eigenhändige Abschrift obiger Korrespondenz mit zahlreichen historischen Noten. Der Druck dieser Briefe mit Kornmentar war von dem historischen Pariser Comité genehmigt und beschlossen, verfiel aber, mit dem Kriege, in Vergessenheit. Mein summarischer Bericht an den Präfekten über den Inhalt des Ankaufs liegt noch vor ${ }^{1}$ ); jedenfalls war die Kaufsumme der sieben Foliobănde (Fr. 216) gut angewendet; sie ist einzureihen in eine der besten Massregeln des letzten französischen Präfekten.

1) Rapport M. le prèfet du Bas-Rhin sur un achat de 7 volumes in $8^{\circ}$. se rattachant au fonds de l'Intendance Strassbourg 1866. chez B.L. in 12'. - Das Manuskript kam aus der Verlassenschaft einer Dame de Serilly, Tochter eines Intendanten aus dem mittäglichen Frankreich. 
Die auf "Zweibrücken« bezüglichen Akten sind nicht sehr zahlreich; der Inhalt ist ebenfalls nicht ausnehmend merkwürdig, nur bieten sie für Strassburg besonderes Interesse durch eine hohe damit verknüpfte Persönlichkeit; ich meine den Prinzen Max Joseph von Zweibrücken-Birkenfeld, den späteren König Max I. von Bayern.

Es hiesse hier Eulen nach Athen tragen, wollte ich bis zu Otto von Wittelsbach und dann zur Abzweigung der kurpfälzischen Linie hinaufsteigen, darauf die vielen Abzweigungen der letzteren verfolgen und endlich zu einem letzten Nebenzweige gelangen, der in der Person des Prinzen Max die Rechte aller ausgestorbenen Linien zusammenfassend, im Jahr 1799 zur (theilweisen) Herrschaft gelangte.

In dem letzten Dezennium vor der französischen Revolution war Obrist Max von Zweibrücken, Inhaber des französischen Regiments Royal Alsace, eine in Strassburg sehr beliebte populäre Persönlichkeit; seine Apanage war vermuthlich sehr mässig; er hatte nur seine Epauletten und seinen Degen aufzuweisen; allein er prangte in voller Jugendkraft, war von den Damen wohlgelitten; die Blicke folgten ihm, wenn er durch die Strassen schritt. - In seinem Hotel - der jetzigen Kommandantur - ist sein Sohn Ludwig der erste geboren.

Ich kannte in meiner ersten Lebenshälfte mehrere Personen, die mit dem Prinzen Max in persönlicher Verbindung gestanden. Unter diesen darf ich die Familie des Generals v. Coëhorn bezeichnen; es war ein freundschaftliches Verhältniss, das noch später dem zweiten Sohne des französischen Generals zu Gute kam, da er als Attachẻ der bourbonischen Gesandtschaft in München bei 'Hofe gute Aufnahme fand.

Auch von anderer Seite kamen mir mehrfache auf den künftigen König von Bayern bezügliche Anekdoten zu; sie stellen den chevaleresken Charakter des Mannes und des Militärs in blendendes Licht. Welch günstigen Eindruck er hinterliess, erhellt noch aus einem spätern wenig beachteten Nebenumstande. Mehr als ein Decennium nach seiner Erhebung auf den Thron widmete ihm Moritz Engelhard, der Verfasser eines jetzt kostbar gewordenen Auszugis aus dem hortus deliciarum der Herrad von Landsberg, dieses mit Abbildungen versehene Werk. Wohl dachte der Herausgeber nicht, dass er seinem fürstlichen Gönner und sich selber ein Denkmal stiftete, welches durch die letzte Kriegskatastrophe einen doppelten 
Werth erhält. Bei dieser Gelegenheit bewahrheitet sich wieder das Sprichwort: habent sua fata libelli.

Strassburg und der Elsass hafteten fest im Gedächtniss und im Herzen des Königs von Bayern. Wohl mancher gebildete Strassburger, der sich in München eine Audienz bei dem ehemaligen Colonel de Royal Alsace erbat, mochte dies erproben.

Was nun die Skripturen der ehemaligen churpfäzischen und zweibrückischen Linie anbelangt, muss ich mich kurz fassen. - Die Vogtei Bischweiler bildet den merkwürdigsten Punkt in diesem Bereiche, und hier tritt selbstverständlich die Einführung der Zwinglischen Reform im 16. Jahrhundert und die Einwanderung französischer kalvinistischer Hugenotten im 17. Jahrhundert hervor. In unseren Akten bietet der Streit beider Nationalitäten im Schooss beider so nahe verwandten Kirchen und beider Pfarrer ein unerquickliches Schauspiel. - Von den Schrecken des dreissigjährigen Kriegs blieb Bischweiler nicht verschont. - Ueber diese innern oft widerwārtigen Ereignisse hebt sich immer wieder die herzgewinnende Gestalt des Prinzen Max und einiger ihm innig verbundenen Wesen. Geschichte und Roman berühren sich in dieser privilegirten Existenz; überwuchern wird beide einmal die Legende; sie wird meist zur psychologischen Wahrheit, wenn man von Verwaltungsakten gar nicht mehr spricht.

Zeit und Raum gebieten mir peremtorisch, andere Fächer des Civilarchives - z. B. das Adelsdirektorium, die Grafschaft Mömpelgard, die Grafschaft Sponheim geradezu aufzugeben, und mich, leider ebenfalls cursorisch der zweiten Hauptabtheilung, dem geistlichen Archiv zuzuwenden. Um vieles bedeutender, mit inhaltschweren Pergamenten überladen, bietet sie sich unserm Blick; nicht einmal in ihren Hauptzügen lässt sie sich zusammenfassen. Meine für das grössere Publikum des Elsass berechnete Uebersicht über die einzelnen Gruppen behandelt die weitschichtige Sammlung nur in ihren Hauptbestandtheilen ${ }^{1}$ ); und selbst aus diesem Extrakt darf ich es hier nicht wagen die allgemeinen Lineamente zu zeichnen. Finden sich jetzt noch bereitwillige Leser für die halb wissenschaftliche, halb gemeinfassliche Abhandlung, worin ich Licht und Schatten soviel möglich unpartheiisch vertheilte, so darf ich ein

1) Lettres sur les Archives departementales du Bas-Rhin. Strassburg 1862. chez Piton. in $8^{\circ}$. 2. Ausgabe. 
nachsichtiges Urtheil über den damals beabsichtigten Zweck erwarten.

Den Eingang in das Sanktuarium bilden selbstverständlich die Hauptpergamente des vormaligen Bisthums Strassburg; das jetzige umfasst bekanntlich nicht mehr denselben Sprengel, lässt einen Theil auf dem rechten Rheinufer liegen, fält nördlich vom Selzbach ab bis an die Lauter, und umfasst dagegen südlich noch den Sundgau. Grandidier stellte in seinem sogenannten Tresor des Chartes, Armoire des Chartes, Armoire historique die vorzüglichsten Pergamente auf. Da bot sich denn gleich zu allem Anfang das schon durch Schoepflin apokryphisch erklärte Testament der heiligen Ottilie, angeblich aus dem 8. Jahrhundert stammend, in der Realität eine dem 11ten zukommende Fälschung. Ich konnte, bei einigen Gelegenheiten, nicht die Frage über die geschichtliche Existenz der Heiligen umgehen und fand mich eingeklemmt zwischen den Lagern der Strenggläubigen und der kritischen Schule, welche letztere, durch Professor Roth in Basel vertreten, sich am Anfang der fünfziger Jahre unbarmherzig gegen die Legende erklärte. Zum Vertheidiger der Persönlichkeit Ottiliens hatte sich Louis Levrault ${ }^{1}$ ), in seiner Geschichte und Beschreibung des Berges aufgeworfen; zu Oberehnheim, fast am Fusse des pittoresken Hohenburgs ansässig, vertraut mit jedem Fusspfad, mit jedem alterthümlichen Steine, von der gallokeltischen Umwallung der Bergeskuppe, den Römerstrassen ab, bis zu den byzantischen Kirchen, Klöstern und Kapellen, in den Thalschluchten und am Abhang der Vorhügel, musste er sich zu seiner Advokatur von Hause aus berufen fühlen, und das that er auch, mil all dem Apparate, den ultramontane Gelehrsamkeit seit Jahrhunderten aufgehäuft. Der konfessionelle Streit im Elsass übertrug sich ebenfalls auf das archäologische Gebiet; in dem Comité dẹ historischen Gesellschaft fand Louis Levrault befreundete, warme Anhänger. Andererseits war es schwer, den Kritizismus, der jede Ueberlieferung abläugnete, nicht in mehrerem berechtigt $\mathrm{zu}$ finden: Schreiber dieser Zeilen stellte sich auf den Standpunkt, dass Papst Leo IX., als er Ottiliens Heiligsprechung genau in der Mitte des 11. Jahrhunderts vollzog, nachdem von den Karolingern ab eine fortlaufende Tradition über die heilige Aebtissin von Hohenburg sich erhalten, nicht alles aus der Luft gegriffen habe; dass von Ottilien, die an den Stamm-

1) Gestorben den 4. Mai 1876. 
baum der Ahnen des heiligen Pabstes sich anknüpfte, vielleicht Familienurkunden sich erhalten hatten. Der Vermittler konnte es selbstverständlich nicht beiden Theilen zu Recht machen; er liess einiges fallen, anderes stehen. Es haben wohl im Bereich der archäologischen lokalen Forschung keine Streitfragen die Kämpfer so leidenschaftlich erregt. Nur für den strengen Kritiker ist die Sache heigelegt und gegen Ottilien entschieden. Nach wie vor werden indess Pilger hundertweise zu dem apokryphen Grabe der Heiligen hinaufsteigen, unbekümmert um die Angriffe der Freidenker; die Kritiker werden mitleidig heruntersehen auf den sblinden Aberglauben * und dem unberufenen Friedensrichter die Thüre weisen.

Es ist mir wohl gestattet, dem Panegyriker des Ottilienberges und dessen Legenden einige Zeilen zu widmen. Mit ihm ging eine der liebenswürdigsten Persönlichkeiten des Elsass zu Grabe. Unbestritten sind seine Verdienste unı das Münzwesen von Strassburg, das er in einem gehaltreichen, beschreibenden und geschichtlichen Werke behandelte. Hatte er doch jahrelang an dem hotel de la monnaie «, als königlicher Controleur gewaltet ${ }^{1}$ ). Vielseitige gediegene Beiträge zu dem Bulletin der historisch-archäologischen Gesellschaft und der Revue d'Alsace hat er geliefert, den Ausgrabungen in der Umgegend von Oberehnheim vorgestanden. Im Jahre 1856 führte ich ihm den berühmten Archäologen Eduard Gerhard zu. Sein gastfreundliches, patriarchalisches Haus bot mir mehrmals bei meinen sonntäglichen Ausflügen ein willkommenes Asyl.

Unter den ältesten, im Trésor des Chartes bewahrten Urkunden finden sich einige von Ludwig dem Frommen. Sie wurden einmal, auf Befehl der Regierung, zur Abschrift an die Académie des inscriptions versendet. Den Auftrag besorgte Präfekt Migneret persönlich und nahm bei seiner Rückkehr die Dokumente wieder in Empfang, einem langen Zurückhalten vorzubeugen, wie dies dem hortus deliciarum der Herrad beim Grafen Bastard widerfuhr. Wer konnte damals ahnen, dass gerade dieses pflichtgetreue Zurückfordern durch Prof. Jung dem köstlichen Bande nach Jahren verderblich werden sollte!

Nach meiner Ansicht bezieht sich eine der merkwürdigsten dieser karolingischen Urkunden nicht auf das Elsass, sondern auf die Insel Reichenau.

1) Essai sur l'histoire de la monnaie de Strassbourg. - Strassbourg 1842. un vol. in $8^{\circ}$. - chez Berger-Levrault. 
Dessen Inhalt besteht in einer einfachen Bestätigung der Privilegien der Abtei, und ist an den Abt Heddon gerichtet, der zugleich als Bischof die Basler Diöcese verwaltete. Was meine Vorliebe entschuldigen mag, ist wohl die chronologische tausendjährige Coincidenz von 817 und 1817. In letzterem Jahre bezog die Nichte Napoleon I., die ehemalige Königin von Holland mit ihrem Sohne Louis eine der Reichenau gegenüber gelegenen Villen. Die Jugendjahre des nachherigen französischen Kaisers Napoleon III. verflossen theilweise in dem romantischen Aufenthalt. Dass er und seine Mutter Hortensia öfters, von Arenenberg aus, die Insel mit ihren Kirchen besucht, ist durch gleichzeitige Memoires bestātigt. J. J. Coulmann in seinen sRéminiscenses weiss sehr viel Anziehendes von einem Aufenthalt, den er, der wohlgelittene Freund der ehemaligen kaiserlichen Grössen auf Arenenberg nahm, zu berichten. Die Gräfin von St. Leu (so nannte sich Hortense) und die Grossherzogin von Baden, Stephanie, fuhren nach Reichenau. Von selbst bieten sich die Berührungspunkte zwischen beiden Epochen und den fürstlichen Persönlichkeiten - Karl, der Entthronte, der seine letzte Ruhestätte in der Abteikirche fand - und der künftige Herrscher Frankreichs, dessen ehrgeizige Pläne vielleicht damals schon in seinem fatalistischen Geiste schlummerten. - Coulmann, der geistreiche Elsasser, besuchte noch wenig Monate vor ihrem Tode die hinsiechende Gräfin von St. Leu nach dem verunglückten Napoleonischen Aufstand in Strassburg. War doch der allgemein bespöttelte Unternehmer dieser prätorianischen Schilderhebung keineswegs entmuthigt durch seinen verfrühten Fehlgriff und wiederholte schon vier Jahre später seinen zweiten noch tollkühneren Versuch, bevor er noch einmal nach der Krone griff, um sie wieder, nach längerer Frist, wie Karl der Dicke, zu verlieren.

Ein anderes dieser Karolingischen Pergamente (v. 817) bestātigt den Strassburger Bischof Adeloch im Besitz eines weitläufigen Bezirks des Breuschthals. Hier ist das elsassische Lokalinteresse überwiegend. Der Sarkophag des Bischofs, der in der Sct. Thomaskirche in nächster Nähe des Grabmals des Marschalls von Sachsen aufgestellt ist, vergegenwärtigt die Gestalt dieses vom Kaiser Ludwig dem Frommen reichlich bedachten Würdenträgers.

Selbstverstāndlich sind in der langen Reihenfolge der Strassburger Bischöfe, von dem Augenblick an, da sie unter den Karolingern zu persönlicher, historischer Existenz gelangen, bis auf das achtzehnte 
Jahrhundert herab, fast alle durch mehrfache Dokumente vertreten. Ausgezeichnete Staatsmänner und Krieger, ehrwürdige Prälaten, auch einige verrufene Charaktere treten auf in dieser Bildergalerie. Es gibt wohl wenig Bisthümer, die unter ihren ersten Würdenträgern so viel scharf ausgeprägte Physiognomien und thātig eingreifende Mānner aufweisen, als die Strassburger Diôzzese. Wir treffen da auf die Namen von Eddo, - Karl Martels Freunde, auf Erchanbold, den Freund dreier sächsischer Kaiser und zweier Kaiserinnen, auf seinen Nachfolger Wiederhold, welchen die Legende so grausam behandelte, auf Werinhar, den Freund Heinrich des Heiligen, den Erbauer der romanischen Kathedrale, auf Otto von Hohenstaufen, den freisinnigen Gesetzgeber, auf Konrad von Lichtenberg, den Freund Rudolphs von Habsburg, auf Johannes von Manderscheid, den strammen Vertheidiger der katholischen Kirche in der zweiten Hälfte des Reformationszeitalters - und dann mit diesen bevorzugten Gestalten in schneidendem Kontraste, auf einen Friedrich von Blanckenheim, den Verbündeten des heuchlerischen Ritters Braun von Rappoltstein, auf den verschwenderischen Wilhelm von Diest, auf den letzten Rohan, Cagliostro's Beschützer.

Bescheiden müssen wir uns mil diesen wenigen Griffen in die Namenreihe der Strassburger Prälaten. Der Raum ist zugemessen, und der zurückzulegende Weg verliert sich in weiter Ferne.

Auf welchen Grad die gegenseitige Animositāt und Erbitterung der religiösen Partheien zu Strassburg und im Elsass gediehen, erwies sich mir deutlich bei meiner Veröffentlichung der Korrespondenz des Bischofs Johann von Manderscheid mit seinen Feudalträgern, aus den Jahren 1570-75. Es besteht dieselbe aus einer Reihenfolge von Briefen, worin der Bischof seine adligen Lehenshalter zum Geleite der Prinzessin Elisabeth von Oesterreich dringlich einladet. Die unglückliche Tochter Kaiser Maximilian II. durchzog nämlich zweimal das Elsass, zuerst auf der verhängnissvollen Reise nach Mezières und Paris, wohin sie als Braut des Königs Karl IX. beschieden war, und dann, fünf Jahre später, nachdem sie die Bluthochzeit vom 24. August 1574 miterlebt und als verwittwete Königin zu ihrem Vater nach Wien zurückkehrte. Die anziehende, rührende, melancholische Gestalt der jungen Fürstin erscheint nur vorübergehend im Briefwechsel, den der Bischof mit seinen Vasallen bei diesem Anlasse führte; sie spricht in einem lateinischen Empfehlungsschreiben den Kirchenfürsten um seinen Beistand an für eine in 
Strassburg gefangene Wittwe, Maria Kis; es fallt, wie gesagt, nur ein Streiflicht auf die gebeugte Elisabeth; doch reicht es hin, ihrer Herzensgüte ein Zeugniss auszustellen. Der Hauptinhalt der angeregten Korrespondenz besteht meist aus Entschuldigungsschreiben der Mitglieder des hohen elsassischen Adels, die sich der unbequemen, kostspieligen, verdriesslichen Mahnung des geistlichen Oberhaupts entziehen. Schreiber dieser Zeilen edirte im Jahr 1856 (zuvörderst in der Revue d'Alsace) diese zahlreichen fliegenden, unleserlichen, hāsslich stylisirten Blätter; gewährten sie doch einen Ueberblick über die Bestandtheile des damaligen einheimischen Adels und dessen zerrüttete Finanzen. Ich konnte mich dabei nicht der Verpflichtung entziehen, die gräulichen Szenen der Bluthochzeit zu brandmarken, deren Einfluss auf das zarte Gemüth der jungen Königin hervorzuheben, zu betonen, wie sie gebrochenen Herzens in die theure Heimath zurückkehrte, jeden fürstlichen Heirathsantrag fürderhin ausschlug, ihr Dasein ganz in Werken der Barmherzigkeit aufgehen liess, und zuletzt in einem von ihr gestifteten Kloster ihre Tage schloss.

Diese rein historische, in mässigen Ausdrücken gehaltene Publikation wurde mir von alten Freunden aus dem katholischen Lager sehr übel angerechnet: san solche Ereignisse solle man nicht die Hand legen $\varsigma$. Ich zog mir das französische Sprichwort zu Gemüthe: im Hause eines Erdrosselten sprich nicht vom Strickec.

Ein Zweitesmal, wenig Jahre darauf, sollte ich durch eigene Erfahrung erhärten, wie sehr die Gemüther in Aufregung befangen!

Der Präfekt Migneret ersuchte mich um einen historischen Ueberblick der Geschichte des Unterelsass, zur Einleitung in das grössere von ihm geplante Werk einer umfassenden statistischen und geographischen Beschreibung des Niederrheinischen Departements. Für ein confessionell gemischtes Publikum bestimmt, war mir selbstverständlich ein rein objektiver Aufsatz geboten. Auf engen Raum beschränkt, die Pflicht der strengsten Unpartheilichkeit im Auge behaltend, fasste ich, wie Strobel vor mir gethan, die Geschichte der Reformation in Strassburg möglichst kurz zusammen, und betonte vor allem das Unerquickliche, Tragische der kirchlichen Trennung. Dies eine wurde mir von protestantischen Freunden und Widersachern in hohem Grad übel genommen. Eines Abfalls wagte man mich geradezu anzuklagen; auf der Kanzel von St. Thomā kam es zu unliebsamen, deutlichen Anspielungen. Ich erfuhr bei dieser und anderwärtiger Gelegenheit, dass absonderlich zu lokaler Geschichts- 
schreibung ein Löwenherz nicht überflüssig wäre. Musste sich doch Johannes von Müller von jedem über die Existenz Tells oder Gesslers angeregten Zweifel ferne halten und in verba magistri, d. $\mathrm{h}$. Tschudi's schwören; er hätte sich persönlichen Beleidigungen ausgesetzt, wäre er auch nur schüchtern der gelehrten Kritik des laufenden Jahrhunderts vorausgeeilt.

Als ich im Verlauf meiner übersichtlichen Excurse in den Lettres sur les archives départementales auf die Karthăuser und andere geistlichen Orden zu sprechen kam und zu verstehen gab, dass solche Institute auf psychologische Bedürfnisse reuiger Sünder oder Lebensmüder gegründet seien, bekam ich zwar keine direkten Vorwürfe; man wandte sich indess an den Redakteur des Niederrheinischen Kuriers und bedeutete ihm, dass protestantische Abonnenten sich über solche Aeusserungen in einem liberalen Blatte wunderten. Doch hielt - ich muss retrospektive dies Verfahren beloben - Charles Boersch an seinem Rechte fest und behielt dem freiwilligen Korrespondenten ein freies Terrain vor.

Ich berühre die Kleinigkeiten zum Belege, dass die hiesige Atmosphäre, jetzt wie damals, für diese Art Polemik mit feindlichen Elementen geschwängert ist.

Im Bisthum von Strassburg bleibt wiederum durch die Sachlage, dem hohen Münsterstifte (grand chapitre de Strassbourg) und hohen Chor (grand choeur) ein beträchtlicher Platz anberaumt. Diese Unterabtheilung, die Geschichte und der Inhalt der Dokumente wurden von mir gebührend berücksichtigt; die hervorragendsten Kapitelherrn, die nur aus fürstlichen oder hochadligen Familien gewählt wurden, erwähnt, und diesem kirchlichen, bis auf die Karolinger hinaufreichenden Senat, dem eigentlichen Vertreter der kirchlichen Interessen gegen jeden bischöflichen Eingriff, die erforderliche Stelle angewiesen; da bot sich denn die natürliche Gelegenheit, von einem der ältesten Dokumente $\mathrm{zu}$ sprechen, welches Arnulph der deutsche König im klimakterischen Jahre 888 erliess, auf die illustrirten Stammbäume der Würdentrăger hinzuweisen, und bei den Prozessakten gegen zwei arme als Hexen angeklagte Bauernweiber (a. 1642) die scheusslichen Gerichtsfrevel jener fanatischen Zeit zu besprechen. $\mathrm{Ob}$ nicht insgeheim der Aerger über meinen Liberalismus sich kundgab, wüsste ich nicht zu bestimmen.

Der hohe Chor mit seinen für Bürgerliche berechneten Statuten führte mich auf den bereits gefeierten Grandidier zurück. Der Ge- 
schichtschreiber und Archivar de: Elsasses hatte in dieser geistlichen Korporation ein Asyl und anständige Persorgung gefunden, und sich durch diese Gunst des Zufalls einen Theil seiner Unabhängigkeit bewahrt.

Die zahlreichen, auf Kaiser, hönige, Herzoge, Grafen, Bischöfe und andere geistlichen Würdenträger bezügliche Dokumente konnten nur in Fluge berūhrt werden. Ich musste darauf bedacht sein, ebenfalls den städtischen Kapiteln (zum alten und jungen Scț. Peter etc.) gerecht zu werden. Für das Sct. Thomasstift konnte ich mich auf das Hauptwerk Karl Schmidt's berufen, dasselbe historisch benützen und aufrichtig beklagen, dass die Akademie der inscriptions et belles lettres es nicht mit einem Hauptpreis bedachte.

Die Geschichte des alten Sct. Peterstiftes war von Strobel in einer gehaltreichen Monographie behandelt worden. Ich erinnerte an dic Entstehung des Kollegiatstifts durch die Erbschaft der ländlichen Kapitel von Honau und Rhenau. Wie der launenhafte Rheinstrom das letztere mit dabei gelegener Óertlichkeit verschlungen, ist ein bekanntes Faktum. Sagen, wie bei versunkenen Städten an der Ostsee, knüpften sich an die unglückliche Lokalität. Für die ältere Sct. Peterkirche war der Zuwachs erwünscht, denn sie hatte sich seit ihrer Gründung keiner bedeutenden Glürksgüter erfreut. Unsere Gruppe besteht hauptsāchlich aus Prozessakten. Im Zeitalter der Reformation wurde sie zum .Zankapfel beider Konfessionen. - Das junge Sct. Peterstift reicht wie das andre Schwesterstift hoch in die Elsassische Geschichte hinauf. Seine Hauptakten beziehen sich auf das Oratorium Allerheiligen, und dieses steht wiederum mit Allerheiligen im Schwarzwald in unterwürfiger Verbindung. Die Geschichte und die Dokumente all' dieser Stifter sind eng miteinander verknüpft und verdienten eigentlich, wie die andern Complexe, die wir alsbald näher in's Auge fassten, eine ausführlichere Analyse.

(Schluss folgt.) 